\title{
An experimental study of an LPG tank at low filling level heated by a remote wall fire
}

\author{
F. Heymes ${ }^{\mathrm{a}, *}$, L. Aprin ${ }^{\mathrm{a}}$, A.M. Birk ${ }^{\mathrm{b}}$, P. Slangen ${ }^{\mathrm{a}}$, J.B. Jarry ${ }^{\mathrm{c}}$, H. François ${ }^{\mathrm{c}}$, G. Dusserre ${ }^{\mathrm{a}}$ \\ ${ }^{a}$ Ecole des Mines d'Ales, 30319 Alès, France \\ bepartment of Mechanical and Materials Engineering, Queen's University, Kingston, Canada \\ ${ }^{\mathrm{c}}$ Comité Français du Butane et du Propane, 8, Terrasse Bellini, 92807 Puteaux Cedex, France
}

\begin{abstract}
A B S T R A C T
This paper describes an experimental study of $2300 \mathrm{~L}$ pressure vessels exposed to remote fire heating by a natural gas fuelled wall fire simulator. The tanks were filled to $15 \%$ capacity with commercial liquid propane. The flame intensity and distance were varied to study the effect of different heating levels on the tank and its lading.

The fire simulator is first characterized with tests including fire thermocouples, radiative flux meters and thermal imaging. With the appropriate positioning of a target tank it is possible to get very realistic fire heat fluxes at the tank surface.

Three tests were conducted with the $2300 \mathrm{~L}$ tanks filled to $15 \%$ capacity with propane. The tanks were positioned at three different distances from the wall fire resulting in measured average peak heat flux at the tank surfaces ranging between 24 and $43 \mathrm{~kW} \mathrm{~m}^{-2}$. The data shows rapid rise in vapour space wall temperatures, significant temperature stratification in the vapour space, and moderate rate of pressure rise. These results provide excellent data for the validation of computer models used to predict the response of pressure vessels exposed to moderate heating from a remote fire.
\end{abstract}

Keywords:

BLEVE

LPG tank

Remote fire

Scale fire testing

Pressure relief valve

\section{Introduction}

Accidental fire exposure of pressure vessels holding dangerous goods is an active topic of research around the world. In many cases researchers are interested in tanks that are engulfed or partially engulfed in pool fires or large jetting fires. However thermal radiation from remote fires is also of great interest. For example, tanks located near forest fires (Heymes et al., 2013; Heymes, Aprin, Ayral, Slangen, \& Dusserre, 2013; Rossi, Simeoni, Moretti, \& LeroyCancellieri, 2011) or burning buildings (Birk, 2000) may suffer failure if the fire intensities are high enough.

When a tank is heated by fire we are interested in how quickly the vapour space wall will heat up and how quickly the tank internal pressure will rise. These depend on many factors including:

- fire size, surface emissive power, and geometry

- tank geometry, orientation and distance relative to the fire

- initial lading temperature

- liquid fill level

\footnotetext{
* Corresponding author. Tel.: +33 466782729; fax: +33 466782701.

E-mail address: frederic.heymes@mines-ales.fr (F. Heymes).
}

- PRV set pressure and flow capacity

- local winds

This paper presents detailed experimental data on the response of tanks at low fill levels to remote fires, with no direct contact of the flames with the tank. There can however be possibility of convective heating of the tank by hot air and combustion products outside of the flame volume. The fires were generated using a wall fire simulator. The results include fire characterization, radiative heat flux at the tank surface, tank wall temperatures, liquid temperature, tank pressure and vapour space temperature distribution.

In order to characterize the fire rig, radiative heat fluxes and infrared recordings were performed. The overall radiative heat flux emitted by the fire was then deduced by theoretical considerations (the solid flame model, SFM) and compared to infrared data. In the SFM, the visible flame is idealized as a solid body, with a simple geometrical shape and with thermal radiation emitted from its surface. The contribution of non-visible zones of the fire plume to the radiative heat flux is usually not taken into account. The SFM model is easy to use and gives results in acceptable agreement with experimental data. In the SFM, the radiative heat flux per unit area reaching a remote target is given by: 
$q=\tau \cdot F \cdot E$

where $F$ is the view factor, $E$ the surface emissive power of the visible flame, and $\tau$ the transmittivity of the air (or combustion gases) layer between the flame and the target. The atmospheric transmittivity corresponds to the fraction of thermal radiation that is transmitted from the fire to the target; it is a function of atmospheric humidity, the concentration of carbon dioxide, and distance, and can be calculated using semi-empirical equations. The worst case occurs when the transmittivity is 1 . The surface emissive power of the flame may be calculated as:

$E=\varepsilon \cdot \sigma \cdot T^{4}$

where $\varepsilon$ is the effective emissivity of the flame, $T$ is the flame temperature, and $\sigma$ is the Stefan Boltzmann constant. The view factor $F$ is defined as the fraction of the radiation leaving a surface $A$ that is intercepted by a surface B. Oriented elementary areas $\mathrm{dA}$ and $\mathrm{dB}$ are connected by a line of length $R$, which forms the polar angles $\theta_{\mathrm{A}}$ and $\theta_{\mathrm{B}}$, respectively, with the surface normal vectors $\mathbf{n}_{\mathrm{A}}$ and $\mathbf{n}_{\mathrm{A}}$. The values of $R, \theta_{\mathrm{A}}$ and $\theta_{\mathrm{B}}$ vary in function of the position of the elemental areas on $A$ and $B$. Assuming that both surfaces emit and reflect diffusely, and that the radiosity is uniform, the view factor can be defined as:

$F_{\mathrm{AB}}=\frac{1}{\mathrm{~A}} \int_{\mathrm{A}} \int_{\mathrm{B}} \frac{\cos \theta_{\mathrm{A}} \cos \theta_{\mathrm{B}}}{\pi R^{2}} \mathrm{dAdB}$

The heat flux emitted by surface $A$ and received by surface $B$ is then calculated from equation (1). On complex cases, the view factor can be computed by a finite element method. This theory was used to calculate heat fluxes emitted by the fire setup.

\section{Experimental design}

\subsection{Fire apparatus}

The fire was configured as a wall measuring $3 \times 8 \mathrm{~m}$. With the fire burning this area could expand to approximately $4 \times 8 \mathrm{~m}$ or even larger. The fire fuel was natural gas. The burner system consisted of an array of $50 \mathrm{~mm}$ pipe with $2 \mathrm{~mm}$ holes drilled at $45^{\circ}$ angles above and below the horizontal plane. In total there were approximately 800 holes. The natural gas pressure was nominally in the range of 5-10 bar. There were metal panels painted black between the pipes. These panels would be heated by the fire and would radiate as near black bodies. Fig. 1 shows a picture of the

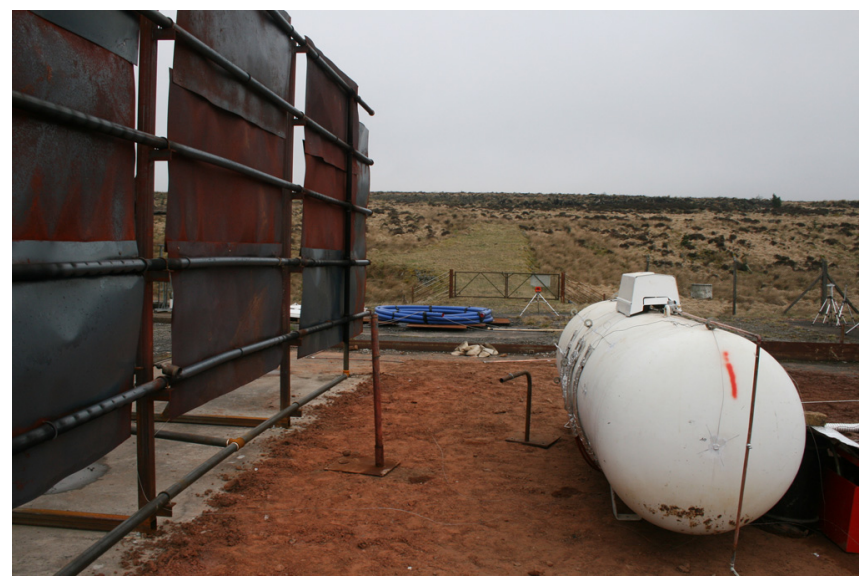

Fig. 1. Picture of tank located beside the wall fire simulator. burner rig beside the tank. In the experiments the fire heat transfer to the tank was modified by varying the distance between the fire and the tank. The fire temperature and size could also be modified by varying the natural gas pressure.

\subsection{Tank details and test matrix}

The tests involved the same size tank in all cases $(2300 \mathrm{~L})$. The following table (Table 1 ) gives a summary of the tank details. The tank was equipped with 23 type $\mathrm{K}$ thermocouples welded at the outside face of the steel. 8 type $\mathrm{K}$ thermocouples were put inside to measure fluids temperatures ( 2 in the liquid and 6 in the gas). A pressure gauge recorded the internal pressure. 2 radiative heat flux meters were fixed at the steel to measure incident heat flux. The location of these heat flux meters was determined theoretically to be at the highest incident heat flux points (Fig. 2). This location was a position $70^{\circ}$ down from the tank top, on the side facing the fire, with an angle $30^{\circ}$ from the vertical plane. It has to be noticed that the tank was equipped with a standard pressure relief valve and commercial devices to supply gas: valve, pressure regulator, copper pipe. The pressure sensor was put at the end of the copper pipe, at a distance of $5 \mathrm{~m}$ from the tank.

8 tests were performed. Tests 4,5 and 6 aimed to characterize the fire rig with the thermal imager (FLIR SC4000) and flux meters (CAPTEC). No tank was put in front of the flames during these tests. Tests 2, 7 and 8 were performed with LPG tanks located at different distances from the fire, for a 20 min burn. Tests 1 and 3 are not reported in this work.

\section{Results}

\subsection{Fire apparatus characterization}

The fire was designed as a rectangular radiating wall. An FLIR SC 4000 thermal imaging system was used to view the fire at a distance of $25 \mathrm{~m}$. There was a $2 \mathrm{~mm}$ thick window (ZnSe) in front of the camera optics. The combined effect of the window and the atmospheric attenuation reduced the flux at the camera sensing element to 0.79 of the actual. An example of picture is given on Fig. 3 .

A vertical analysis line was drawn and the temperature profile was reported on the same picture. Three zones can be defined. The main zone (zone 1 ) corresponds to the area where the metal panels painted black between the pipes increase and homogenise and emitted heat flux. A second zone corresponds to the free flames area without panels; the emitted heat flux remains high but significantly lower than in zone 1 . The last zone (zone 3 ) corresponds to hot gases with a lower temperature and low emissivity, the temperature drops below the inferior sensitivity limit of the camera $\left(<350^{\circ} \mathrm{C}\right)$. An image processing routine on all tests revealed that the most part of emitting surface is located in a rectangular shape $4 \times 8$ meters.

In the tests presented here the distance between the tank and firewall was varied between 2.3 and $3.8 \mathrm{~m}$ (Fig. 4). However, the fire thickness could vary depending on the wind and natural gas

Table 1

Summary of tanks details.

\begin{tabular}{ll}
\hline Tank details & \\
\hline Volume & $2300 \mathrm{~L}$ approx. \\
Diameter & $1.0 \mathrm{~m}$ \\
Overall length & $2.6 \mathrm{~m}$ \\
Wall thickness & $6.1-6.2 \mathrm{~mm}$ \\
End type & $2: 1$ elliptical \\
Steel & A48P1 \\
PRV set pressure and flow capacity & 19.6 bar $1.33 \mathrm{~m}^{3} \mathrm{~s}^{-1}$ \\
\hline
\end{tabular}




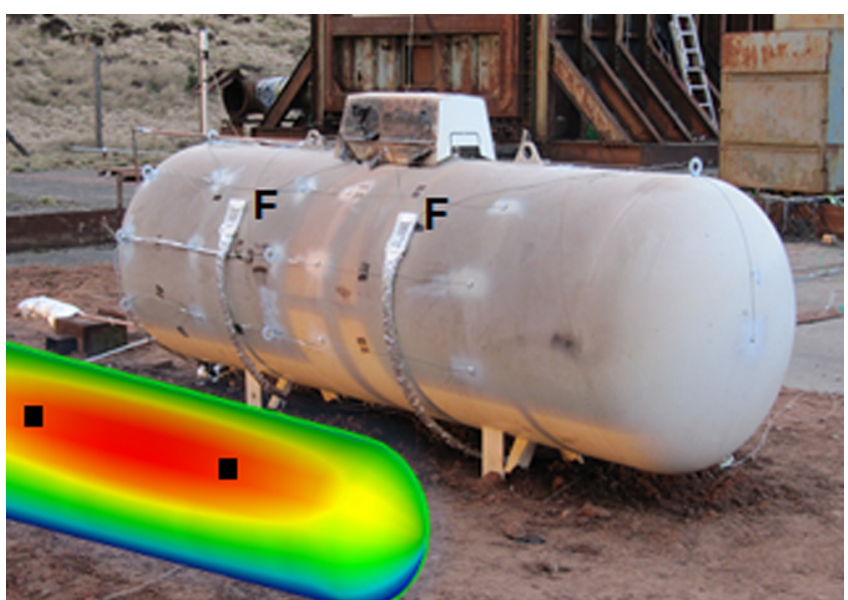

Fig. 2. Experimental tank, location of radiative heat flux sensors (F). pressure variations. The varying fire temperature and thickness would affect the fire emissive power. Another effect of fire thickness variation is that the separation distance between tank and fire could have been different and this of course would affect the view factor between the tank and fire. Fire tilting due to air currents and wind will also affect the view factor.

Since the radiation source is composed by the thick flame and the hot panels, it is not easy to determine where to locate the surface of the solid flame model. In the next calculations an adjustment was made to the separation distance in an attempt to account for the thickness of the fire. From video images the fire thickness was approximated to be between 0.5 and $1 \mathrm{~m}$. In the calculation presented here we made a parametric study: a range of possible view factor and fire emissive power will be given in the next results. The lowest view factor supposes that the radiating surface corresponds to the hot panels; the highest value supposes a radiating wall located at $0.8 \mathrm{~m}$ in front of the hot panels. The corresponding fire emissive powers are deduced from the data. No attempt was made to account for the fire leaning over the tank. This of course would also increase the view factor significantly. Three tests were conducted to characterize the burner system. These tests are summarized in Table 2.

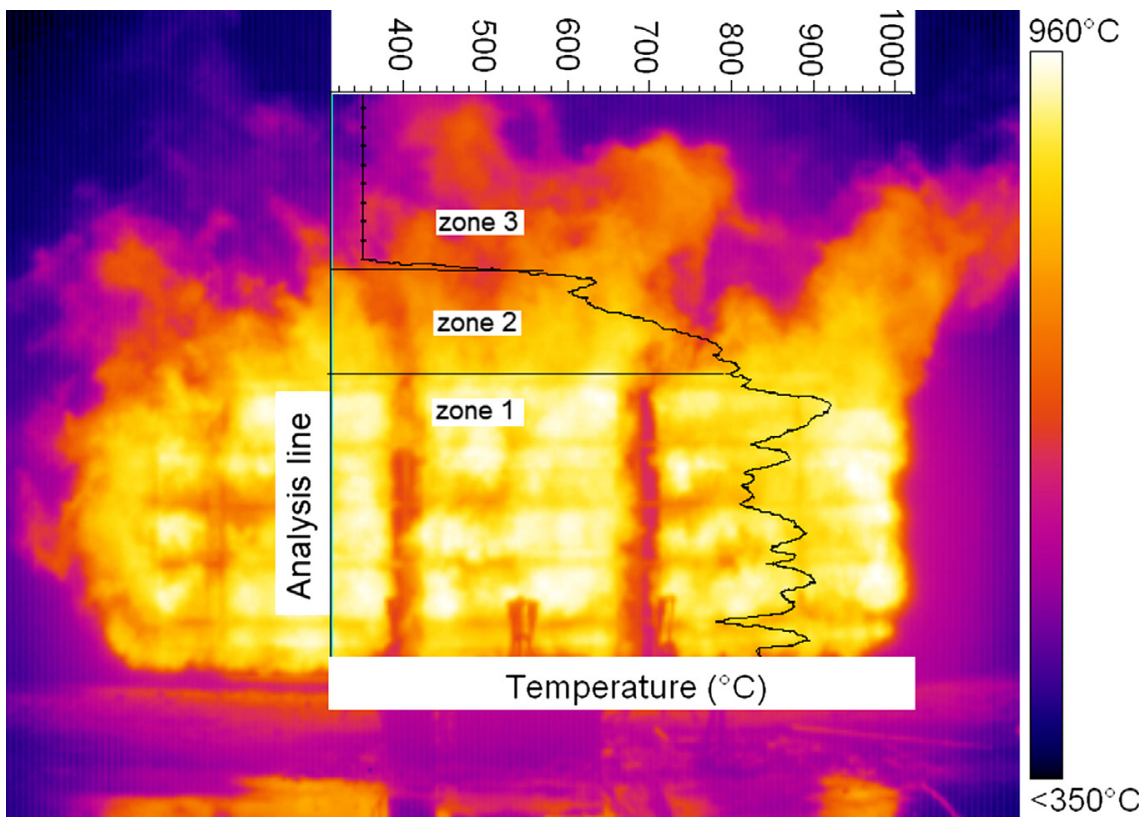

Fig. 3. Thermal image of fire in test 5 .
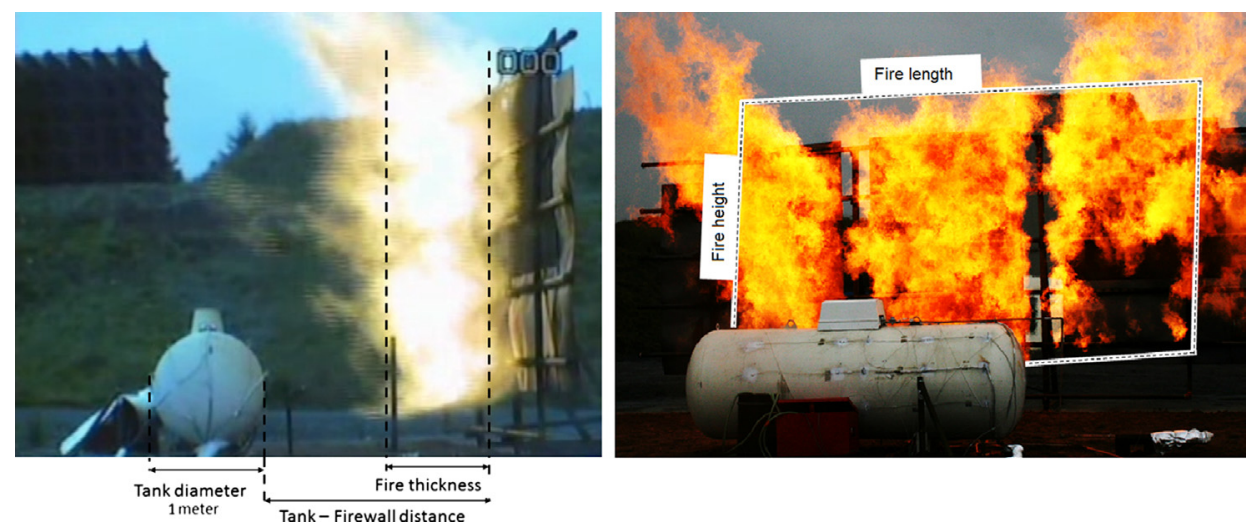

Fig. 4. Firewall parameters. 
Table 2

Summary of fire characterization tests.

\begin{tabular}{|c|c|c|c|c|c|c|c|}
\hline Test & $\begin{array}{l}\text { Average fuel } \\
\text { pressure (bar) }\end{array}$ & $\begin{array}{l}\text { Distance to } \\
\operatorname{tank}(\mathrm{m})\end{array}$ & $\begin{array}{l}\text { Min peak flux at } \\
\operatorname{tank}\left(\mathrm{kW} \mathrm{m}^{-2}\right)\end{array}$ & $\begin{array}{l}\text { Max peak flux } \\
\text { at tank }\left(\mathrm{kW} \mathrm{m}^{-2}\right)\end{array}$ & $\begin{array}{l}\text { Average peak flux } \\
\text { at } \operatorname{tank}\left(\mathrm{kW} \mathrm{m}^{-2}\right)\end{array}$ & $\begin{array}{l}\text { Approx. Peak } \\
\text { view factor (-) }\end{array}$ & $\begin{array}{l}\text { Approx. Fire emissive } \\
\text { power }\left(\mathrm{kW} \mathrm{m}^{-2}\right)\end{array}$ \\
\hline 4 & 4.6 & 3.8 & 12 & 24 & 17 & $0.32-0.38$ & $45-53$ \\
\hline 5 & 5.5 & 3.8 & 17 & 29 & 22 & $0.32-0.38$ & $58-69$ \\
\hline 6 & 5.3 & 2.7 & 18 & 52 & 30 & $0.44-0.50$ & $60-68$ \\
\hline
\end{tabular}

Table 3

Summary of estimated fire emissive powers.

\begin{tabular}{|c|c|c|c|}
\hline Test & Estimated emissive power of fire $\left(\mathrm{kW} \mathrm{m}^{-2}\right)$ & Calculated BB temperature of fire $\left({ }^{\circ} \mathrm{C}\right)$ & Average BB temperature from IR camera $\left({ }^{\circ} \mathrm{C}\right)$ \\
\hline 4 & $45-53$ & $672-713$ & No data \\
\hline 5 & $58-69$ & $734-778$ & 800 \\
\hline 6 & $60-68$ & $743-775$ & 775 \\
\hline
\end{tabular}

The estimated emissive powers of the fire simulator are well below known heat fluxes for large fires. For example data shows that large fires can have emissive powers greater than $100 \mathrm{~kW} \mathrm{~m}^{-2}$ (see for example Rew, Hulbert, \& Deaves, 1997). Rossi et al. (2011) used a fire heat flux of $117 \mathrm{~kW} \mathrm{~m}^{-2}$ to estimate safety distances for wildland fires.

By considering max peak flux at tank instead of average peak flux, the fire emissive power probably exceeded $100 \mathrm{~kW} \mathrm{~m}^{-2}$ at some points in time in test 6 . It is believed the difference between test 4 and 5 was probably the increased fuel pressure and also wind effects leading to different view factors and fire emissive power.

This has been accounted for in the calculation of the corrected black body (BB) temperature of the fire shown in Table 3. That table gives a summary of the thermal imager data compared to the measured flux at the tank and the estimated view factors.

A good agreement was found between IR and calculated data. The data suggest the solid flame surface should be located at the panels' location and behaved nearly as a black body with surface emissive powers in the range of $70 \mathrm{~kW} \mathrm{~m}^{-2}$ and black body radiating temperatures of $780^{\circ} \mathrm{C}$. With future planned improvements the wall fire will likely have an effective black body temperature from 850 to $900{ }^{\circ} \mathrm{C}$.

\subsection{Tests with the LPG tanks}

Three tests were conducted with tanks filled to 15\% capacity with propane. The tests were conducted at three distances from the fire. In the same manner as above, the fire emissive power was calculated theoretically. No IR data was measured since the BLEVE possibility could damage the expensive FLIR camera. A thermocouple was put near the centre of the fire. The time-averaged local heat flux to the tanks varied between 24 and $43 \mathrm{~kW} \mathrm{~m}{ }^{-2}$. The following table (Table 4) gives a summary of the measured and estimated fire conditions.
As can be seen the fire emissive power was not consistent from test to test. This is attributable to different wind conditions and differences in fuel pressure delivered to the burner. Case 8 was the worst fire scenario. For an average heat flux of $43 \mathrm{~kW} / \mathrm{m}^{2}$ the emitted heat flux from the fire varied in the range $77-84 \mathrm{~kW} / \mathrm{m}^{2}$, depending on the view factor. Note that the fire emissive power probably exceeded $112 \mathrm{~kW} \mathrm{~m}^{-2}$ (i.e. $912{ }^{\circ} \mathrm{C}$ ) for brief periods in test 8 . This is more in line with expectations of emissive power in large luminous fires.

Fig. 5 shows the measured heat flux at the tank surface (i.e. at tank mid length $70^{\circ}$ down from the tank top) during test 8 . The average reading was $43 \mathrm{~kW} \mathrm{~m}^{-2}$ which agrees well with the calculation for a distance of $2 \mathrm{~m}$. In this test the tank was $2.3 \mathrm{~m}$

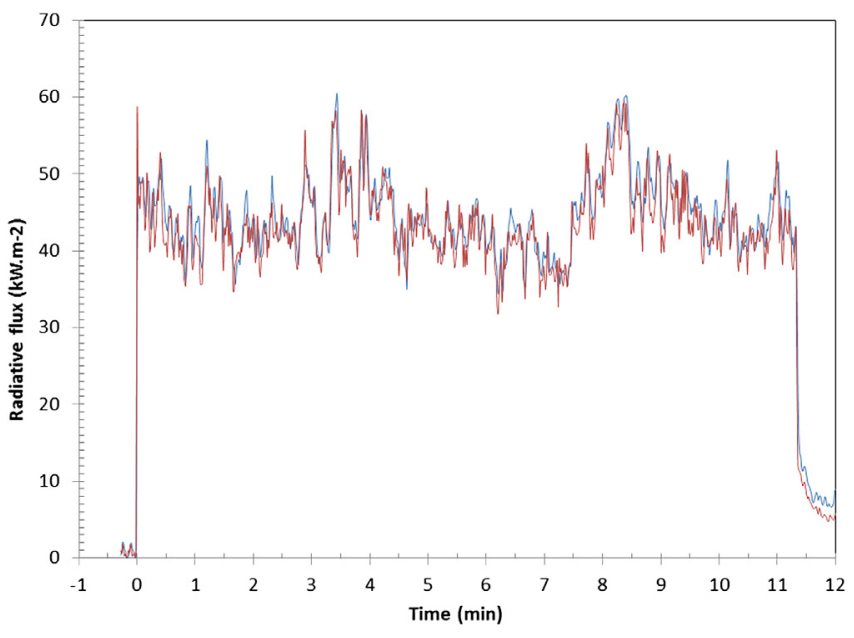

Fig. 5. Measured radiative heat flux at the tank surface for Test 8 (tank at $2.3 \mathrm{~m}$ ).

Table 4

Summary of tank test conditions.

\begin{tabular}{|c|c|c|c|c|c|c|}
\hline Test & $\begin{array}{l}\text { Estimated } \\
\text { distance } \\
\text { to fire }(\mathrm{m})\end{array}$ & $\begin{array}{l}\text { Peak heat flux } \\
\text { range at tank } \\
\text { surface }\left(\mathrm{kW} \mathrm{m}^{-2}\right)\end{array}$ & $\begin{array}{l}\text { Estimated } \\
\text { view factor }\end{array}$ & $\begin{array}{l}\text { Estimated average } \\
\text { fire emissive } \\
\text { power }\left(\mathrm{kW} \mathrm{m}^{-2}\right)\end{array}$ & $\begin{array}{l}\text { Calculated fire BB } \\
\text { temperature }\left({ }^{\circ} \mathrm{C}\right)\end{array}$ & $\begin{array}{l}\text { Measured average } \\
\text { fire Temp }\left({ }^{\circ} \mathrm{C}\right)\end{array}$ \\
\hline 2 & $3-3.8$ & $\begin{array}{l}15-42 \\
26 \text { average }\end{array}$ & $0.32-0.38$ & $68-81$ & $777-823$ & 750 \\
\hline 7 & $2-2.8$ & $\begin{array}{l}8-41 \\
24 \text { average }\end{array}$ & $0.44-0.50$ & $48-55$ & $688-719$ & $\mathrm{NR}^{\mathrm{a}}$ \\
\hline 8 & $1.5-2.3$ & $\begin{array}{l}32-58 \\
43 \text { average }\end{array}$ & $0.52-0.56$ & $77-84$ & $807-827$ & 830 \\
\hline
\end{tabular}

${ }^{a} \mathrm{NR}=$ not recorded. 
Table 5

Summary of results for fire tests with tank.

\begin{tabular}{|c|c|c|c|c|c|c|}
\hline Test & $\begin{array}{l}\text { Test duration } \\
(\min )\end{array}$ & $\begin{array}{l}\text { Peak pressure } \\
\text { (bar) }\end{array}$ & $\begin{array}{l}\text { Peak wall temperature } \\
\left({ }^{\circ} \mathrm{C}\right)\end{array}$ & $\begin{array}{l}\text { Peak vapour temperature } \\
\left({ }^{\circ} \mathrm{C}\right)\end{array}$ & $\begin{array}{l}\text { Peak liquid temperature } \\
\left({ }^{\circ} \mathrm{C}\right)\end{array}$ & $\begin{array}{l}\text { Initial temperature } \\
\left({ }^{\circ} \mathrm{C}\right)\end{array}$ \\
\hline 2 & 20 & 12.9 & 294 & 192 & 30 & 11 \\
\hline 7 & 16 & 11.5 & 261 & 180 & 21 & 12 \\
\hline 8 & 11 & $17^{\mathrm{a}}$ & 386 & 258 & 36 & $17^{\mathrm{b}}$ \\
\hline
\end{tabular}

a In test 8 the pressure transducer failed at 11 min. At that time the tank was leaking propane near the tank top and the fire was shut down. The PRV eventually opened.

b Test 8 was stopped and restarted. When the test was restarted the liquid temperature was approximately $25^{\circ} \mathrm{C}$.
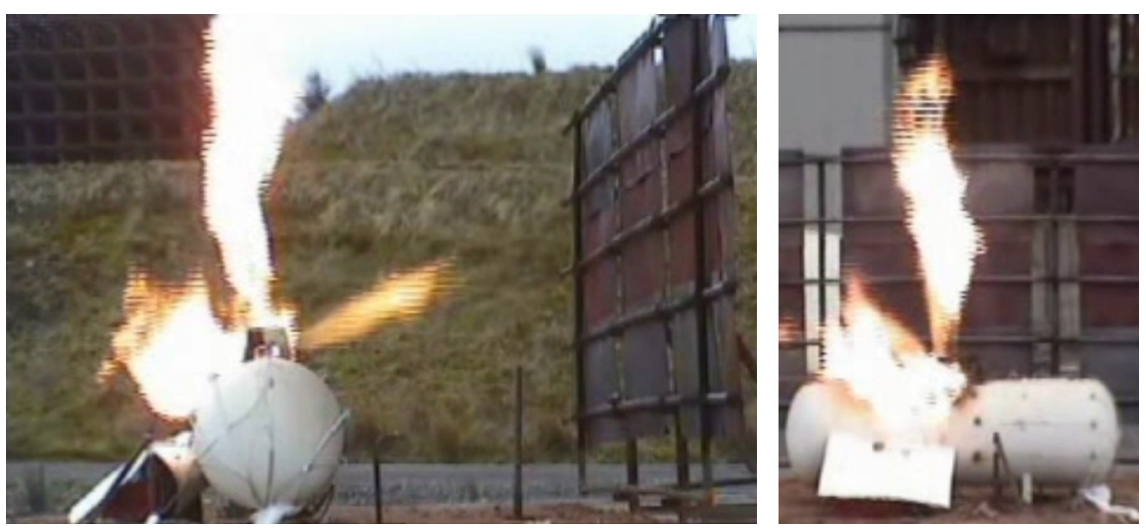

Fig. 6. Ignited release of propane from fittings.

away from the wall. This is expected to be the point of maximum heat flux on the tank surface.

It should be noted that these heat flux values only apply near the centre of the tank where the view factor is highest. This is a local heat flux on the tank surface. The heat flux to the tank surface will vary over the tank surface because of the varying view angles to the fire. It is clear from the heat flux measured at the tank surface that test 8 resulted in the most severe heating of the tank.

In the literature (see for example Zarate, Arnaldos, \& Casal, 2008 ) it is reported that a heat flux of $37.5 \mathrm{~kW} \mathrm{~m}^{-2}$ can cause damage to process equipment or collapse of mechanical structures. The average measured heat fluxes shown in Fig. 4 are below this value and were not expected to lead to catastrophic failure of the tanks. Heat fluxes that are known to lead to catastrophic failure are generally higher. For example, engulfing fire tests involving full scale rail tank cars by (Townsend, Anderson, Zook, \& Cowgill, 1974) involved heat fluxes in the range of $90-100 \mathrm{~kW} \mathrm{~m}^{-2}$ and this resulted in tank rupture in $24 \mathrm{~min}$. Smaller scale tanks such as the ones in this test series have been tested by (Birk \& VanderSteen, 2006) and they failed in less than 10 min with heat fluxes in the range of $90-100 \mathrm{~kW} \mathrm{~m}^{-2}$.

A summary of results from the three tests are presented in Table 5. Of these tests, test 8 experienced the highest heat flux and the most consistent fire conditions. Detailed results will be presented for test 8 . Table 5 presents a summary of the results of the three tests.

Test 8 was very interesting because it documented a sequence of events that is common in fire exposure incidents of tanks. The fire exposure itself was probably not sufficient to cause a thermal rupture of the tank. However, the heating was sufficient to cause fittings on the vessel to fail, and cause a release of propane. This is common of certain types of fittings made of low melting temperature metals. This release was then ignited and this lead to additional heating of the tank. The release produced a significant jetting fire that heated the tank top (Fig. 6). At this point in the test the main fire was extinguished but the jetting fire continued.
Unfortunately the pressure transducer failed at this point and pressure data was not recorded.

Fig. 7 shows the measured tank wall temperatures from test 8 . As can be seen from the figure, the main fire was extinguished at 11 min. However, leaking propane continued to burn as a jet impinging the top of the tank. This resulted in very high wall temperatures being recorded. At 20 min the highest wall temperature measurement (wall T11) changed dramatically suggesting the thermocouples detached from the tank. It is not certain the wall actually reached a temperature of $750{ }^{\circ} \mathrm{C}$. Measurements of wall temperatures under the conditions of jet fire heating are difficult because of possible conduction errors. A tank like this, under full pressure at the PRV set pressure would be expected to fail quickly if the wall was heated to $750{ }^{\circ} \mathrm{C}$. In this test no significant plastic deformation of the tank wall was observed (Fig. 8). It is possible the pressure was low at this point in the test.

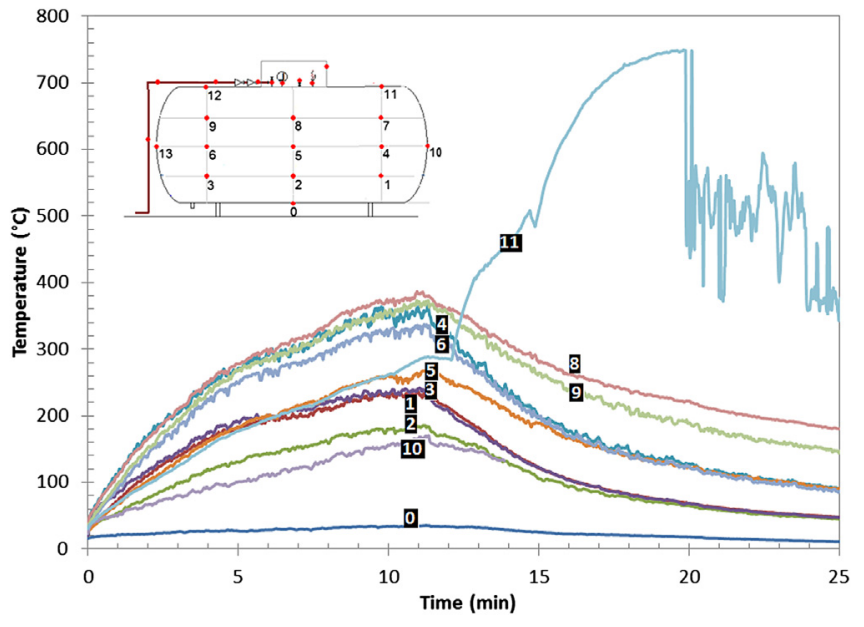

Fig. 7. Measured wall temperatures in test 8 . 

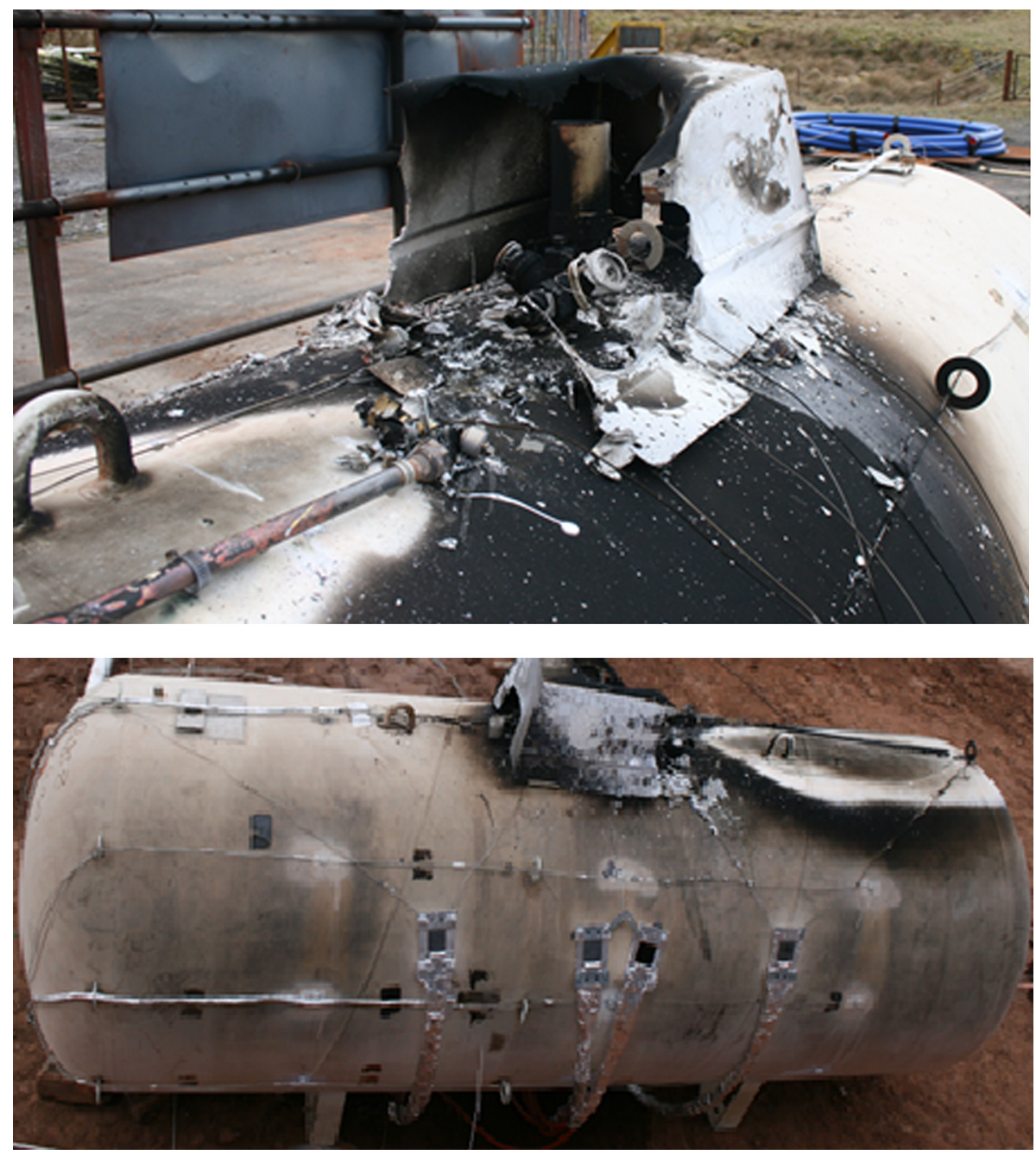

Fig. 8. Tank pictures after experiment in test 8 .

Fig. 9 presents the measured vapour space temperatures and tank pressure vs time for test 8 . As can be seen the pressure transducer failed at $12 \mathrm{~min}$. Although the pressure data was lost it is possible to see the activity of the pressure relief valve in the measured vapour temperatures. When the vapour temperatures suddenly drop this indicates the PRV has opened. When they rise again the PRV has closed. The data suggests the PRV opened three separate times. We should not conclude from this that the pressure remained near the PRV set pressure of 17 bar. It is very possible the spring in this PRV was softened by the high temperatures at the top of the tank. The PRV may have popped at pressures well below 17 bar. It is quite possible that this spring softening saved this tank from failure. This has been seen in other fire tests of tanks (see Birk Cunningham, Ostic, \& Hiscoke, 1997).

Fig. 9 also shows very significant temperature stratification in the vapour. This hot vapour provided almost no cooling of the vapour space wall near the top of the tank.

\section{Computer modelling}

For the prediction of tank failure it is critical to be able to estimate the vapour space wall temperature and the tank pressure. With these one can estimate the degradation in the wall strength with temperature and we can calculate the hoop stress to see if failure is indicated. Predicting the wall temperature and tank pressure requires us to do an energy balance on the wall and on the lading. For a remote fire condition the heat transfer to the vapour space wall includes:

- direct radiation from the fire

- radiation to the surroundings

- possible heat convection to or from the surroundings

- heat conduction through the tank wall

- internal convection to the vapour

- internal radiation from the wall

- radiation to the inner surface of the wall from the vapour, walls and the liquid surface

For a wall element far from the liquid surface we can usually ignore heat conduction. This means we can treat a wall element as a lumped capacity system. A simplified energy balance can be used to predict the rise for this case.

$$
\begin{aligned}
& \rho c w \frac{\mathrm{d} T}{\mathrm{dt}}=F_{1 f} \sigma \varepsilon_{w}\left(\varepsilon_{f} T_{f}^{4}+\left(1-\varepsilon_{f}\right) T_{\mathrm{amb}}^{4}\right)+\left(1-F_{1 f}\right) \sigma \varepsilon_{w} T_{\mathrm{amb}}^{4} \\
& +F_{1 \text { liq }} \sigma \varepsilon_{\text {liq }} T_{\text {liq }}^{4}+\left(1-F_{1 \text { liq }}\right) \varepsilon_{w} \sigma T_{\mathrm{wav}}^{4}-2 \sigma \varepsilon_{w} T_{w}^{4} \\
& -h_{\text {inside }}\left(T_{w}-T_{\text {vapav }}\right)-h_{\text {out }}\left(T_{w}-T_{\text {air }}\right)
\end{aligned}
$$

where $T$ is the temperature, $c$ is the specific heat, $w$ is the wall or wall thickness, $t$ is the time, $\rho$ is the density, $F$ is the view factor, $\varepsilon$ is 


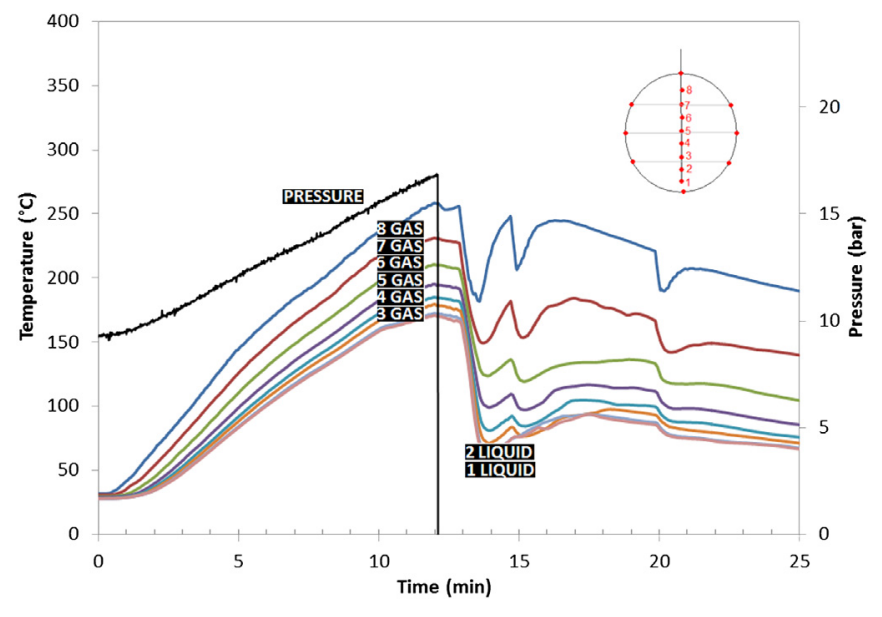

Fig. 9. Measured fluids temperatures and tank pressure in test 8 .

the emissivity, 1 is the surface element on tank, $f$ is the fire, av is the average, liq is the liquid, vap is the vapour, $h$ is the convective coefficient.

This assumes all surfaces are of high emissivity so that multiple reflections of radiation can be ignored. Convection in the vapour space is due to free convection unless the PRV is open. Free convective coefficients are expected to be quite low in the range of $5-20 \mathrm{~W} \mathrm{~m}^{-2} \mathrm{~K}^{-1}$. On the outside of the tank we would expect free or forced convection coefficient in the range of $5-20 \mathrm{~W} \mathrm{~m}^{-2} \mathrm{~K}^{-1}$ depending on the wind conditions. For a white painted tank we would expect surface emissivity in the range of $0.87-0.92$. For the inside of the tank the emissivity could be lower depending on the condition and surface treatment of the wall.

With a tank near a fire one would expect the air temperature between the tank and the fire to be highly variable. If there is no wind one would expect the air to be moving toward the fire so the air between the tank and the fire would be cool and it would act to cool the tank. However, if the wind is blowing the fire towards the tank then the air temperatures near the tank could be high and convective heating of the tank may take place.

For the energy balance on the lading we must account for all the heat that enters the vapour and liquid from the inside wall of the tank. In this simple analysis we will ignore temperature stratification in the liquid and vapour. We have assumed the lading is isothermal and at saturation conditions. The total heat to the lading is determined from the integral of the convection and radiation heat transfer from the tank inner wall:

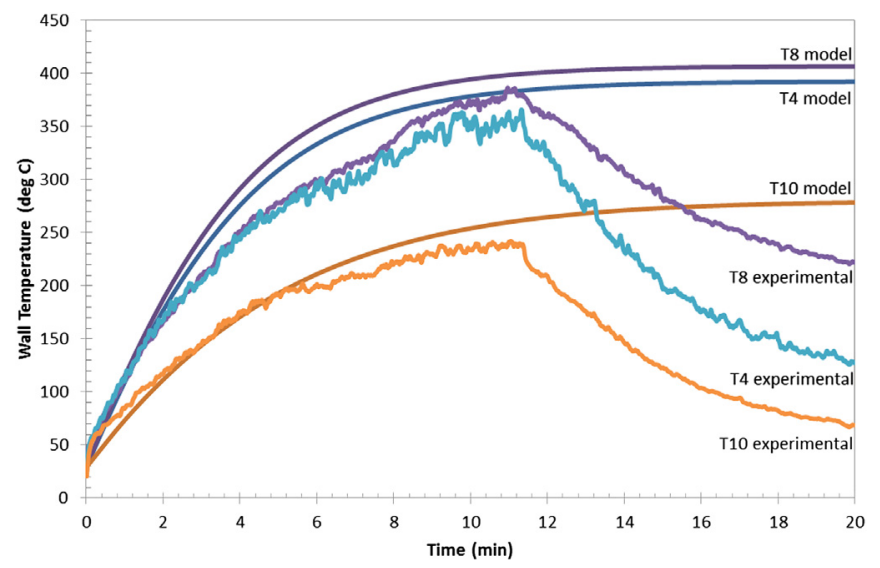

Fig. 10. Predicted and Measured Wall temperatures, Test 8, assuming air near tank is at ambient temperature.

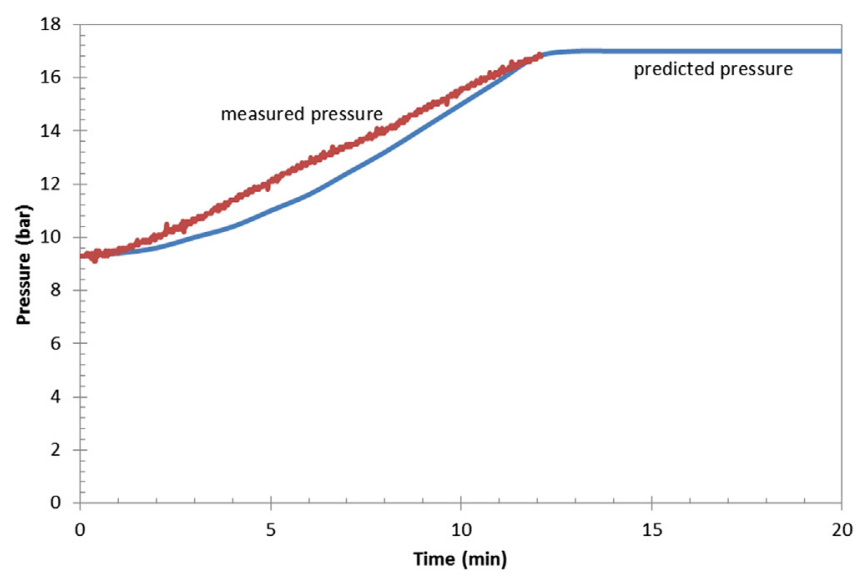

Fig. 11. Predicted and Measured Pressure, Test 8, assuming air near tank is at ambient temperature.

$\dot{Q}=\int q \mathrm{dA}=\int\left[F_{1 \text { liq }} \varepsilon_{w} \sigma\left(T_{w}^{4}-T_{\text {liq }}^{4}\right)+h_{\text {in }}\left(T_{w}-T_{\text {fluid }}\right)\right] \mathrm{dA}$

LPG boiling was studied by (Aprin, Mercier, \& Tadrist, 2011), we assumed a very high convective coefficient $\left(h=5000 \mathrm{~W} \mathrm{~m}^{-2} \mathrm{~K}^{-1}\right)$. This basically forces the liquid wetted wall temperature to be very near the liquid temperature. We have assumed the propane vapour is transparent to the wall and liquid radiation. It is also assumed all radiation falling on the liquid is absorbed by the liquid (i.e. emissivity of liquid $=1$ ). The process in the tank is one of heating at constant total volume. That is:

$\frac{\mathrm{d} V}{\mathrm{~d} t}=\frac{\mathrm{d}(m v)}{\mathrm{d} t}=0$

where $V$ is the tank volume, $m$ is the mass, $v$ is the specific volume. The energy balance for tank as a control volume is:

$\frac{\mathrm{d} U}{\mathrm{~d} t}=\dot{Q}-\dot{m} \boldsymbol{h}_{\mathrm{gprv}}$

The mass balance is:

$\frac{\mathrm{d} m}{\mathrm{~d} t}=-\dot{m}$

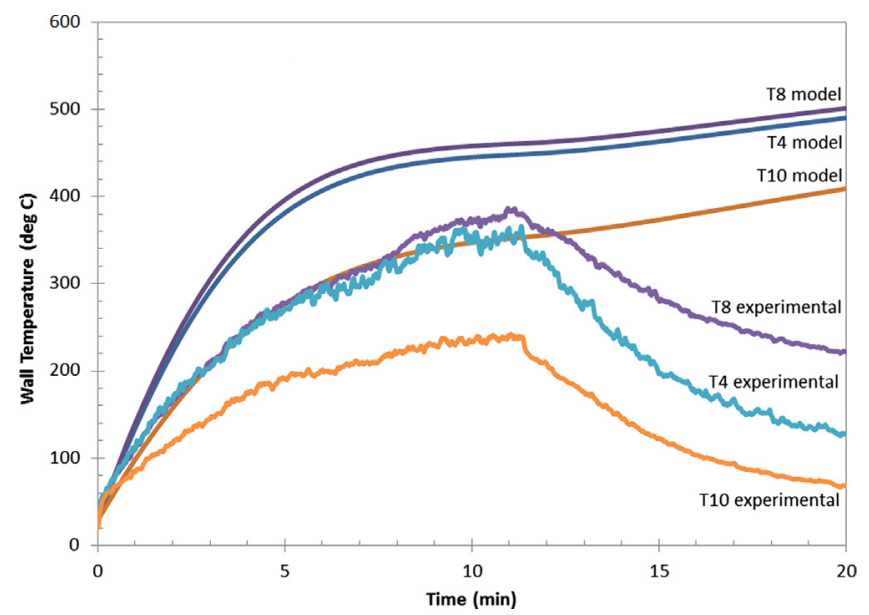

Fig. 12. Predicted and Measured Wall temperatures, Test 8 , assuming air near tank is at $500{ }^{\circ} \mathrm{C}$. 


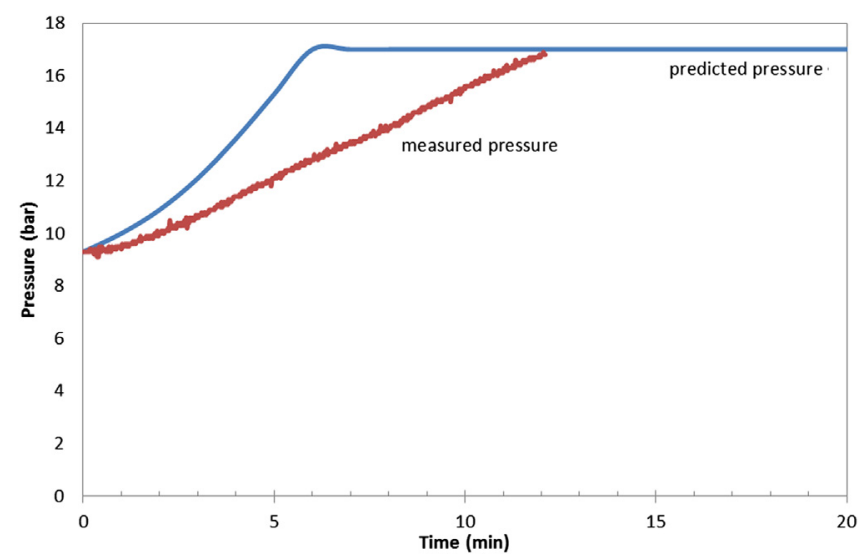

Fig. 13. Predicted and Measured Pressure, Test 8 , assuming air near tank is at $500{ }^{\circ} \mathrm{C}$.

where $U$ is the internal energy, hgprv is the enthalpy of the gas leaving the tank from the pressure relief valve, $\dot{Q}$ is the total heat rate to lading, $m$ is the liquid and vapour mass, $m$ is the pressure relief valve (vapour flow), $t$ is the time.

These equations have been programmed using an explicit finite difference scheme so that some simple simulations could be performed and compared to the measured data. We have considered the following case:

- Fire emissive power $80 \mathrm{~kW} \mathrm{~m}^{-2}$

- Tank surface emissivity is 0.9

- Tank initial temperature is $20^{\circ} \mathrm{C}$

- Low liquid fill (fill $=0.15$ )

- Wall fire $4 \times 8 \mathrm{~m}$ at an effective distance of 1.5 (i.e. incident flux at tank surface $43 \mathrm{~kW} \mathrm{~m}^{-2}$ )

- No heating from ground (i.e. no reflection of radiation, nothing burning on the ground, ground at ambient temperature)

We will then assume two extreme cases

- air between tank and fire is at $500{ }^{\circ} \mathrm{C}$ and exterior convection coefficient is $h=20 \mathrm{~W} \mathrm{~m}^{-2}$ (hot air scenario)

- air between tank and fire is at $20{ }^{\circ} \mathrm{C}$ and $h=20 \mathrm{~W} \mathrm{~m}^{-2}$ (cool air scenario)

Fig. 10 shows the predicted and measured peak tank wall temperature as a function of time for the cool air scenario and for test 8. Fig. 11 shows the predicted vs measured pressure for the cool air scenario and test 8 . As can be seen the pressure is well predicted and the wall temperature is reasonably well predicted.

Fig. 12 and Fig. 13 show the same simulations and data but for the hot air scenario. As can be seen the tank pressurizes much faster and the wall temperature increase significantly.

As can be seen from the figure the two scenarios result in a significantly different peak wall temperature. The measured wall temperature agrees best with the cool air scenario. It should be noted that the radiative heat flux to the tank wall in Test 8 varied between approximately 32 and $58 \mathrm{~kW} \mathrm{~m}^{-2}$ with an average around $58 \mathrm{~kW} \mathrm{~m}^{-2}$. Here we have modelled the local peak flux as $58 \mathrm{~kW} \mathrm{~m}^{-2}$.

\section{Conclusions}

This work focused on the impact of a distant fire on an LPG tank. Incident radiative heat flux from a remote fire depends on the size of the fire and distance to the target. The intensity of incident flux is usually lower than in engulfed scenarios (jetting fire, pool fire) but may remain high enough to cause serious damage to the target. In case of an LPG tank, this work highlighted that very significant rises in wall temperature and tank pressure can be expected and can lead to the activation of pressure relief devices. Fire heating that may not be sufficient to cause rupture of the tank may be sufficient to cause the failure of certain fittings. This may lead to a leak of propane that could be ignited to cause self-heating of the tank. If this happens it is possible that this additional heating could cause the tank to fail.

Experimental data collected during the tests showed that the heating led to significant temperature gradients in the vapour space. These gradients dissipated when the PRV opens due to convective mixing.

It was possible to predict the response of the tank with reasonable accuracy using simple models that account for fire radiation, external convection, internal convection and radiation, and energy and mass conservation. Chosen parameters (convective coefficients e.g.) seemed to be relevant.

As an important recommendation, pressure fittings on tanks should not be made of low melting temperature materials because even minor fire exposure may lead to releases of propane and this could escalate the fire situation.

\section{Acknowledgements}

The authors thank the CFBP (Comité Français du Butane Propane) for their financial support and the GL Noble Denton Spadeadam test site for the technical collaboration.

\section{References}

Aprin, L., Mercier, P., \& Tadrist, L. (2011). Local heat transfer analysis for boiling of hydrocarbons in complex geometries: a new approach for heat transfer prediction in staggered tube bundle. International Journal of Heat and Mass Transfer, $54,4203-4219$.

Birk, J. L. (2000). A study of fire heating of a propane tank near a burning building. Journal of Applied Fire Science, 9, 173-199.

Birk, A. M., Cunningham, M. H., Ostic, P., \& Hiscoke, B. (1997) Fire tests of propane tanks to study BLEVEs and other thermal ruptures: detailed analysis of medium scale test results. Transport Canada report TP $12498 \mathrm{E}$.

Birk, A. M., \& VanderSteen, J. D. J. (2006). On the transition from non-BLEVE to BLEVE failure for a $1.8 \mathrm{~m}^{3}$ propane tank. ASME Journal of Pressure Vessel Technology, 128, 648-655.

Heymes, F., Aprin, L., Forestier, S., Slangen, P., Jarry, J. B., François, H., et al. (2013). Impact of a distant wildland fire on an LPG tank. Fire Safety Journal, 61, 100-107. http://dx.doi.org/10.1016/j.firesaf.2013.08.003i.

Heymes, F., Aprin, L., Ayral, P. A., Slangen, P., \& Dusserre, G. (2013). Impact of wildfires on LPG tanks. Chemical Engineering Transactions, 31, 637-642.

Rew, P. J., Hulbert, W. G., \& Deaves, D. M. (1997). Modelling of thermal radiation from external hydrocarbon pool fires. Process Safety and Environmental Protection, 75, 81-89.

Rossi, J. L., Simeoni, A., Moretti, B., \& Leroy-Cancellieri, V. (2011). An analytical model based on radiative heating for the determination of safety distances for wildland fires. Fire Safety Journal, 46, 7.

Townsend, W., Anderson, C. E., Zook, J., \& Cowgill, G. (1974). Comparison of thermally coated and uninsulated rail tank-cars filled with LPG subjected to a fire environment. US DOT Report.

Zarate, L., Arnaldos, J., \& Casal, J. (2008). Establishing safety distances for wildland fires. Fire Safety Journal, 43, 10 